BMJ Open

Diabetes

Research

\& Care

\section{Diabetes case finding in the emergency department, using HbA1c: an opportunity to improve diabetes detection, prevention, and care}

To cite: Hng T-M, Hor A, Ravi S, et al. Diabetes case finding in the emergency department, using HbA1c: an opportunity to improve diabetes detection, prevention, and care. BMJ Open Diabetes Research and Care 2016;4:e000191. doi:10.1136/bmjdrc-2015000191

Received 31 December 2015 Revised 19 April 2016 Accepted 21 April 2016
CrossMark

For numbered affiliations see end of article.

Correspondence to Dr Tien-Ming Hng; tien-ming. hng@health.nsw.gov.au

\section{ABSTRACT}

Objective: We assessed the efficacy of routine glycated hemoglobin (HbA1C) testing to detect undiagnosed diabetes and prediabetes in an urban Australian public hospital emergency department (ED) located in an area of high diabetes prevalence.

Methods: Over 6 weeks, all patients undergoing blood sampling in the ED had their random blood glucose measured. If $\geq 5.5 \mathrm{mmol} / \mathrm{L}$ ( $99 \mathrm{mg} / \mathrm{dL}), \mathrm{HbA} 1 \mathrm{c}$ was measured on the same sample. $\mathrm{HbA} 1 \mathrm{c}$ levels $\geq 6.5 \%$ $(48 \mathrm{mmol} / \mathrm{mol})$ and $5.7-6.4 \%(39-46 \mathrm{mmol} / \mathrm{mol})$ were diagnostic of diabetes and prediabetes, respectively. Hospital records were reviewed to identify patients with previously diagnosed diabetes.

Results: Among 4580 presentations, 2652 had blood sampled of which 1267 samples had HbA1c measured. Of these, 487 (38.4\%) had diabetes (either

$\mathrm{HbA} 1 \mathrm{C} \geq 6.5 \%$ or a prior diagnosis), and a further 347 $(27.4 \%)$ had prediabetes. Among those with diabetes, $32.2 \%$ were previously undiagnosed.

Conclusions: Routine $\mathrm{HbA1C}$ testing in the ED identifies a large number of people with undiagnosed diabetes and prediabetes, and provides an opportunity to improve their care.

\section{INTRODUCTION}

Diabetes has traditionally been diagnosed by the $75 \mathrm{~g}$ oral glucose tolerance test $(75 \mathrm{~g}$ OGTT), but recent adoption of glycated hemoglobin (HbAlc) as a diagnostic tool for high-risk individuals has simplified the diagnostic process. ${ }^{1-3}$ Underdetection remains a major barrier to prevention of diabetes and associated complications. Targeted HbAlc testing of high-risk populations could enhance the detection of diabetes and prediabetes. The purpose of this study was to test this hypothesis in patients presenting to a hospital emergency department (ED).

\section{METHODS}

The study was conducted over 6 weeks in the ED of Blacktown-Mt Druitt Hospital, located in the western suburbs of Sydney, Australia. This is

\section{Key messages}

- We demonstrate that glycated hemoglobin measurement undertaken in the setting of an emergency department is an effective and feasible means of finding cases of diabetes and prediabetes particularly in an area known to have a high prevalence of diabetes.

- Approximately a third of patients tested were previously unaware that they had diabetes.

- Earlier detection of prediabetes provides an opportunity to introduce measures that may prevent progression to diabetes.

an area of high diabetes prevalence. ${ }^{4}$ Opportunistic blood glucose measurements were undertaken in all non-pregnant individuals $\geq 16$ years of age who had blood collected after presenting to the ED, irrespective of the presenting problem. HbAlc was automatically measured if the random glucose was $\geq 5.5 \mathrm{mmol} / \mathrm{L}(99 \mathrm{mg} / \mathrm{dL})$. This cut-off level was chosen based on another Australian ED study ${ }^{5}$ and a substudy that we undertook (unpublished). In this substudy, HbA1c measurements were undertaken in 50 patients presenting through ED with random glucose levels $<5.5 \mathrm{mmol} / \mathrm{L}(<99 \mathrm{mg} / \mathrm{dL})$. Only three individuals were noted to have HbA1c levels $\geq 6.5 \%$ and the glucose cut-off of $\geq 5.5 \mathrm{mmol} / \mathrm{L}$ $(99 \mathrm{mg} / \mathrm{dL})$ was deemed reasonable.

In patients who re-presented within the study period, HbAlc testing was undertaken only on the first presentation. As per American Diabetes Association recommendations, diabetes was diagnosed if $\mathrm{HbAlc} \geq 6.5 \%$ $(48 \mathrm{mmol} / \mathrm{mol})$ and prediabetes was diagnosed if $\mathrm{HbAlc}$ was between $5.7 \%$ and $6.4 \%$ (39-46 mmol/mol). ${ }^{1}$ HbAlc was measured using a turbidimetric inhibition immunoassay on a Siemens Dimension Vista 1500 platform. Coefficient of variation was $2.9 \%$ and $2.4 \%$, at a HbAlc level of $5.7 \%$ and 
$10.1 \%$, respectively. Demographic data, previous diagnosis of diabetes, and coding information were obtained from the hospital's database. This study was discussed with and approved by the Human Research Ethics Committee of the Western Sydney Local Health District.

\section{RESULTS}

There were 4580 presentations to the ED. Using the methodology described, 1267 HbAlc measurements were available (figure 1). Female patients accounted for $47.3 \%$ of results obtained. Three hundred and seventynine HbAlc tests were not performed due to multiple presentations, insufficient blood sampling or issues related to the automation of HbAlc measurement. In this cohort, diabetes was present in $38.4 \%$ (HbAlc $\geq 6.5 \%$ or a prior diagnosis if $\mathrm{HbAlc}<6.5 \%$; table 1 ).

Of the patients identified with diabetes, $45.2 \%$ were female and $32.2 \%(157 / 487)$ were newly diagnosed. Of newly diagnosed patients, $61.8 \%$ had mild diabetes (HbAlc of $6.5-6.9 \%$ or $48-52 \mathrm{mmol} / \mathrm{mol}$ ). Three hundred and forty-seven (27.4\%) of HbAlc sampled patients had levels consistent with prediabetes (HbAlc $5.7 \%-6.4 \%$ or $39-46 \mathrm{mmol} / \mathrm{mol}$ ). The sampling protocol resulted in HbA1c being measured in $59 \%(n=751)$ of admitted patients, and, of these, diabetes was present in $42.4 \%$. Analysis of coding information revealed that $28 \%$ of admissions who were known to have diabetes (either by HbA1c assessment or previously noted in the medical record) were not coded for the diagnosis of diabetes. Of this group, $11 \%$ were previously known to have diabetes, $81 \%$ were newly diagnosed, and the remaining $8 \%$ were coded as impaired glucose regulation.

\section{DISCUSSION}

The key finding from this ED study is that almost two in every five patients tested on available HbAlc samples had diabetes. This is consistent with other studies that indicate a high risk of diabetes in Western Sydney's ethnically diverse, low socioeconomic population. ${ }^{4} \quad 6$ Importantly, one in three patients found to have diabetes were previously unaware of their condition. Additionally, a further $27.4 \%$ had prediabetes, meaning that $65.7 \%$ of patients tested with HbAlc had either

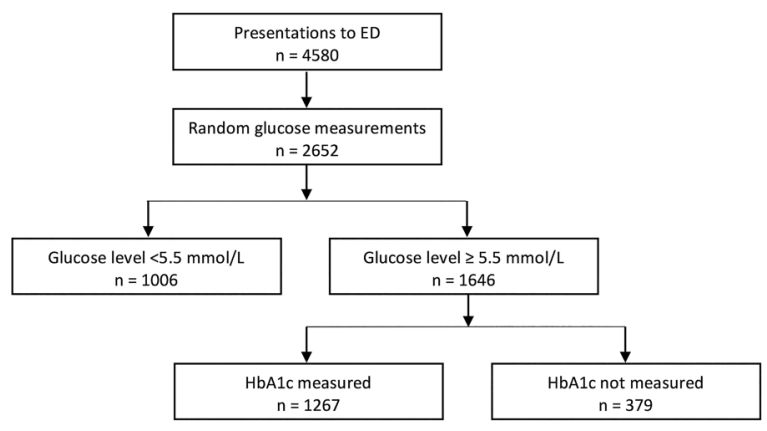

Figure 1 Study profile. ED, emergency department; HbA1c, glycated hemoglobin. diabetes or prediabetes. The use of HbAlc for diabetes case finding in the ED had a high yield in our patient population, but these findings may not necessarily be replicated in locations with a lower prevalence of diabetes. In an Australian tertiary referral hospital's ED in Melbourne, Jelinek $e t a l^{7}$ noted similar rates of dysglycemia but, despite a high diabetes prevalence, the authors did not find screening a feasible exercise due to their reliance on a $75 \mathrm{~g}$ OGTT to confirm the diagnosis.

Diagnosis of diabetes was not confined to the mild end of the spectrum-with a severely elevated HbAlc level $(>9 \%$ or $75 \mathrm{mmol} / \mathrm{mol}$ ) seen in $7.3 \%$ of the entire cohort, and in $10.2 \%$ of newly diagnosed patients. Rapidly identifying admitted patients with poor glycemic control utilizing a test on a single blood sample that does not require any pretest preparation provides an ideal opportunity for intervention by hospital diabetes services. The majority of the newly diagnosed patients had early stage diabetes with HbAlc levels of 6.5-6.9\% (48-52 $\mathrm{mmol} / \mathrm{mol}$ ), providing the ideal opportunity for early intervention to take place before the onset of complications. Almost a third of the individuals diagnosed as having diabetes were not aware of their diagnosis, reflecting the hidden burden of diabetes in our community. This may indicate that current screening practices in primary care are insufficient and further supports opportunistic $\mathrm{HbAlc}$ testing in individuals presenting to hospital, a population seemingly enriched with cases of diabetes. In Australia, universal health insurance (Medicare) covers the cost of HbAlc testing to diagnose diabetes in 'high-risk' individuals. ${ }^{8}$ Our data suggest that a high proportion of patients presenting to ED and requiring blood collection would meet this definition. Use of blood glucose alone for diabetes diagnosis is problematic because of the presence of 'stress hyperglycemia', a pitfall avoided by use of the HbA1c test.

The use of HbAlc to identify prediabetes is supported by the American Diabetes Association. ${ }^{1}$ Progression to diabetes may be prevented if these individuals were provided with achievable lifestyle intervention. This has been shown to be beneficial in prediabetes in several studies such as the Diabetes Prevention Program ${ }^{9}$ and the Finnish Diabetes Prevention Program. ${ }^{10}$ One such lifestyle intervention programme in Australia is the government run Get Healthy initiative. ${ }^{11}$

A novel feature of this study is the use of HbAlc to diagnose diabetes in a non-primary care setting. Previous studies have demonstrated that diabetes screening in an outpatient and a GP setting is feasible. ${ }^{12}$ The visit to $\mathrm{ED}$ is an opportunity for us to detect diabetes in individuals who infrequently seek routine medical care, and who may otherwise go undetected. An earlier ED study of a tertiary referral hospital in Adelaide, Australia, noted a prevalence of undiagnosed diabetes of $11 \%,{ }^{5}$ compared with $32.2 \%$ in this study. This may be because of the highly multicultural population in our study, compared with the overwhelmingly Caucasian population of Adelaide (table 2). 
Table 1 Levels of dysglycemia based on glycated hemoglobin ( $\mathrm{HbA1c}$ ) measurements with subset analysis of individuals newly diagnosed with diabetes

\begin{tabular}{|c|c|c|c|c|c|c|}
\hline \multirow[b]{2}{*}{ Status } & \multicolumn{2}{|c|}{ HbA1c (\%) } & \multicolumn{2}{|c|}{ All patients } & \multicolumn{2}{|c|}{ Admitted patients } \\
\hline & Per cent & $\mathrm{mmol} / \mathrm{mol}$ & $\mathbf{N}$ & Per cent & $\mathbf{n}$ & Per cent \\
\hline No diabetes & $<5.7$ & $<39$ & 433 & 34.2 & 244 & 32.5 \\
\hline Prediabetes & $5.7-6.4$ & $39-46$ & 347 & 27.4 & 188 & 25.0 \\
\hline${ }^{*}$ Known diabetes & $<6.5$ & $<48$ & 81 & 6.4 & 66 & 8.8 \\
\hline \multirow[t]{4}{*}{ Diabetes } & $6.5-6.9$ & $48-52$ & 138 & 10.9 & 80 & 10.7 \\
\hline & $7.0-7.9$ & $53-63$ & 117 & 9.2 & 76 & 10.1 \\
\hline & $8.0-8.9$ & $64-74$ & 58 & 4.6 & 43 & 5.7 \\
\hline & $\geq 9.0$ & $\geq 75$ & 93 & 7.3 & 54 & 7.2 \\
\hline Total & & & 1267 & 100 & 751 & 100 \\
\hline \multicolumn{7}{|l|}{ Subset analysis } \\
\hline \multirow[t]{4}{*}{ New diabetes } & $6.5-6.9$ & $48-52$ & 97 & 61.8 & 52 & 80 \\
\hline & $7.0-7.9$ & $53-63$ & 37 & 23.6 & 10 & 15.4 \\
\hline & $8.0-8.9$ & $64-74$ & 7 & 4.5 & 2 & 3.1 \\
\hline & $\geq 9.0$ & $\geq 75$ & 16 & 10.2 & 1 & 1.5 \\
\hline Total & & & 157 & 100 & 65 & 100 \\
\hline
\end{tabular}

${ }^{*}$ Previously diagnosed with diabetes as noted in the medical record.

For the purpose of funding and performance review, all clinical data on admitted patients are coded using the International Classification of Disease codes. In our cohort, $28 \%$ of patients diagnosed with diabetes based on an elevated HbAlc were not coded as having diabetes, leading to an underestimate in the coded data, and potential underfunding relative to true case complexity. Coding inaccuracies can also result in an overestimation of the number of newly diagnosed individuals as this calculation is dependent on whether they had previously been coded as having diabetes.

The use of HbA1c to diagnose diabetes has limitations as any factor affecting the quantity or quality of the hemoglobin molecule can result in measurement inaccuracies. This has not been accounted for in our study, but would tend to result in an underestimate of diabetes cases. Sampling was only undertaken in individuals who had blood collected, and this introduces a source of bias. It could be argued that the pickup rate for diabetes could be further improved by advocating routine testing in all individuals presenting to the ED.

Another limitation of using HbAlc to diagnose diabetes is the existence of ethnic variability in the measurement that is not explained by glycemic state, structural abnormalities or quantity of the hemoglobin molecule. ${ }^{15-17}$ This is relevant in our multiethnic population where the diagnosis of diabetes can be based on a slight elevation in the HbAlc level. Our study used glucose level as the initial screening step and this would have limited the diagnostic inaccuracies that might have occurred had this not been undertaken.

Diabetes case finding in the ED is justified as there is a significant population with known and undiagnosed diabetes. Following the findings of this pilot, it is intended that routine $\mathrm{HbAlc}$ testing will be the norm in the ED at Blacktown Hospital.

Table 2 Comparison of the top 10 cultural groups (based on country of birth) between the study population and the postcodes within which the respective hospitals are located

\begin{tabular}{|c|c|c|c|c|c|}
\hline \multicolumn{2}{|c|}{ Study population } & \multicolumn{2}{|l|}{ Postcode 2148 (Sydney) $^{13}$} & \multicolumn{2}{|l|}{ Postcode 5041 (Adelaide) $^{14}$} \\
\hline & Population (\%) & & Population (\%) & & Population (\%) \\
\hline Australia & 50.1 & Australia & 53.2 & Australia & 78.4 \\
\hline India & 5.1 & Born elsewhere & 9.4 & UK & 4.6 \\
\hline Philippines & 4.9 & India & 7.5 & Country of birth not stated & 3.7 \\
\hline England & 2.8 & Country of birth not stated & 4.8 & Born elsewhere & 2.7 \\
\hline Fiji & 2.3 & Philippines & 4.7 & Greece & 1.3 \\
\hline Sri Lanka & 2.0 & UK & 2.3 & India & 1.1 \\
\hline Malta & 2.0 & New Zealand & 2.2 & China & 1.1 \\
\hline New Zealand & 1.7 & Fiji & 2.0 & New Zealand & 1.0 \\
\hline Italy & 1.6 & China & 1.9 & Italy & 0.8 \\
\hline Egypt & 1.3 & Malta & 1.1 & Germany & 0.7 \\
\hline
\end{tabular}

Source: Australian Bureau of Statistics Census (2011) data. 
Author affiliations

${ }^{1}$ Western Sydney Local Health District, Blacktown Hospital, Blacktown, New South Wales, Australia

${ }^{2}$ School of Medicine, Western Sydney University, Parramatta, New South Wales, Australia

${ }^{3}$ School of Health and Society, University of Wollongong, Wollongong, New South Wales, Australia

${ }^{4}$ Early Start Research Institute, University of Wollongong, Wollongong, New South Wales, Australia

${ }^{5}$ School of Science and Health, Western Sydney University, Parramatta, New South Wales, Australia

${ }^{6}$ School of Geography and Geosciences, University of St Andrews,

St Andrews, UK

Acknowledgements The authors acknowledge the assistance of Pathology West for $\mathrm{HbA1C}$ assessment and data retrieval, the Health Information Record Service for coding information, and the Executive of Blacktown/Mt Druitt Hospital for supporting the study, particularly for the costs of $\mathrm{HbA1C}$ measurements.

Contributors T-MH assisted in study design and database development, contributed to the discussion, researched and analyzed data, and wrote the manuscript. AH assisted in study design, researched, collected and analyzed data, and wrote the manuscript. SR collected data and assisted with correspondence. XF analyzed data, contributed to the discussion, and reviewed/ edited the manuscript. JL collected data. TA-B contributed to the discussion and reviewed/edited the manuscript. DC contributed to the discussion and concept. MM contributed to the study design and discussion, and reviewed/edited the manuscript. GM conceived the idea, secured institutional support, contributed to the discussion, and reviewed the manuscript.

Competing interests None declared.

Ethics approval Human Research and Ethics Committee of the Western Sydney Local Health District.

Provenance and peer review Not commissioned; externally peer reviewed.

Data sharing statement No additional data are available.

Open Access This is an Open Access article distributed in accordance with the Creative Commons Attribution Non Commercial (CC BY-NC 4.0) license, which permits others to distribute, remix, adapt, build upon this work noncommercially, and license their derivative works on different terms, provided the original work is properly cited and the use is non-commercial. See: http:// creativecommons.org/licenses/by-nc/4.0/

\section{REFERENCES}

1. American Diabetes Association. 2. Classification and diagnosis of diabetes. Diabetes Care 2015;38(Suppl 1):S8-16.
2. d'Emden MC, Shaw JE, Colman PG, et al. The role of HbA1c in the diagnosis of diabetes mellitus in Australia. Med $J$ Aust 2012;197:220-1.

3. World Health Organization Consultation. Use of glycated haemoglobin ( $\mathrm{HbA1c}$ ) in the diagnosis of diabetes mellitus. Diab Res Clin Pract 2011;93:299-309.

4. Astell-Burt T, Feng X, Kolt GS, et al. Understanding geographical inequities in diabetes: multilevel evidence from 114,755 adults in Sydney, Australia. Diab Res Clin Pract 2014;106:e68-73.

5. Valentine NA, Alhawassi TM, Roberts GW, et al. Detecting undiagnosed diabetes using glycated haemoglobin: an automated screening test in hospitalised patients. Med J Aust 2011:194:160-4.

6. Australian Diabetes Map Australia: Diabetes Australia; [updated 6/10/2015. https://http://www.diabetesaustralia.com.au/ tools-e-learning

7. Jelinek GA, Weiland TJ, Moore G, et al. Screening for type 2 diabetes with random finger-prick glucose and bedside $\mathrm{HbA} 1 \mathrm{c}$ in an Australian emergency department. Emerg Med Australas 2010;22:427-34.

8. The November 2014 Medicare Benefits Schedule: Department of Health, Australian Government. http://www.health.gov.au/internet/ mbsonline/publishing.nsf/Content/Downloads-2014-11

9. Knowler WC, Barrett-Connor E, Fowler SE, et al. Reduction in the incidence of type 2 diabetes with lifestyle intervention or metformin N Engl J Med 2002;346:393-403.

10. Tuomilehto J, Lindstrom J, Eriksson JG, et al. Prevention of type 2 diabetes mellitus by changes in lifestyle among subjects with impaired glucose tolerance. $N$ Engl J Med 2001;344:1343-50.

11. NSWHealth. Get Healthy Information and Coaching Service NSW. Australia: NSW Health, 2015 [10 Oct 2015]. http://www. gethealthynsw.com.au/

12. Klein Woolthuis EP, de Grauw WJ, van Gerwen WH, et al. Yield of opportunistic targeted screening for type 2 diabetes in primary care: the diabscreen study. Ann Fam Med 2009;7:422-30.

13. 2011 Census of Population and Housing 2148 (POA2148) $29 \mathrm{sq}$ Kms: Australian Bureau of Statistics; 2011 [updated 17 March 2016. Census data from the Australian Bureau of Statistics]. http://www. censusdata.abs.gov.au/census_services/getproduct/census/2011/ communityprofile/POA2148

14. 2011 Census of Population and Housing 5041 (POA5041) $6.2 \mathrm{sq}$ Kms: Australian Bureau of Statistics; 2011 [updated 17 March 2016. Census data from the Australian Bureau of Statistics]. http://www. censusdata.abs.gov.au/census services/getproduct/census/2011/ communityprofile/POA5041

15. Hare MJ, Magliano DJ, Zimmet PZ, et al. Glucose-independent ethnic differences in $\mathrm{HbA} 1 \mathrm{c}$ in people without known diabetes. Diabetes Care 2013;36:1534-40.

16. Herman WH, Cohen RM. Racial and ethnic differences in the relationship between $\mathrm{HbA} 1 \mathrm{c}$ and blood glucose: implications for the diagnosis of diabetes. J Clin Endocrinol Metab 2012;97:1067-72.

17. Venkataraman K, Kao SL, Thai AC, et al. Ethnicity modifies the relation between fasting plasma glucose and $\mathrm{HbA} 1 \mathrm{c}$ in Indians, Malays and Chinese. Diabet Med 2012;29:911-17. 